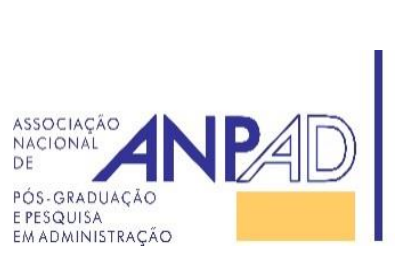
Available online at
http://www.anpad.org.br/bar
BAR, Rio de Janeiro, v. 13, n. 4, art. 7, e160009, Oct./Dec. 2016
http://dx.doi.org/10.1590/1807-7692bar2016160009
(c) BY

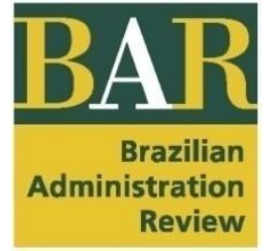

\title{
Service Providers' Willingness to Change as Innovation Inductor in Services: Validating a Scale
}

Marina Figueiredo Moreira ${ }^{1}$ Tomás de Aquino Guimarães ${ }^{1}$ Jean Philippe ${ }^{2}$

Universidade de Brasília ${ }^{1}$ Aix-Marseille Universite/Faculte des Sciences Economiques et de la Gestion ${ }^{2}$

Received 28 January 2016; received in revised form in 4 November 2016 (this paper has been with the authors for two revisions); accepted in 6 December 2016; published online 15 December 2016. Editor's note. Carlo Bellini served as Action Editor for this article. 


\begin{abstract}
This study explores the willingness of service providers to incorporate changes suggested by clients altering previously planned services during its delivery, hereby named Willingness to Change in Services [WCS]. We apply qualitative research techniques to map seven dimensions related to this phenomenon: Client relationship management; Organizational conditions for change; Software characteristics and development; Conditions affecting teams; Administrative procedures and decision-making conditions; Entrepreneurial behavior; Interaction with supporting organizations. These dimensions have been converted into variables composing a WCS scale later submitted to theoretical and semantic validations. A scale with 26 variables resulted from such procedures was applied on a large survey carried out with 351 typical Brazilian software development service companies operating all over the country. Data from our sample have been submitted to multivariate statistical analysis to provide validation for the scale. After factorial analysis procedures, 24 items have been validated and assigned to three factors representative of WCS: Organizational Routines and Values - 12 variables; Organizational Structure for Change - 6 variables; and Service Specificities - 6 variables. As future contributions, we expect to see further testing for the WCS scale on alternative service activities to provide evidence about its limits and contributions to general service innovation theory.
\end{abstract}

Key words: change; services; service innovation; change in services; scale development. 


\section{Introduction}

Service sector has gained prominence among economic and managerial studies since the 1950's as a result of its upward trajectory in developed economies since post-Fordism period (Buera \& Kaboski, 2012), bringing us to contemporary service economies, highly dependent in terms of innovation and knowledge (Gallouj, 2002; Gallouj \& Savona, 2009). As services continuously increase their majority share in world top economies year after year, they also consolidate as top research lines in innovation and management studies, bringing new research questions to light (Kim, Lee, Geum, \& Park, 2012; Mansury \& Love, 2008; Toivonen \& Tuominen, 2009; Vence \& Trigo, 2009). Themes traditionally exploited on researches on innovation subjects are revisited in the light of new production logic associated to services. Innovation determinants, for instance, have been largely explored on industrial economics under multiple theoretical approaches such as science-push or demand-pull since the 1950's (Cainelli, Evangelista, \& Savona, 2006; Di Stefano, Gambardella, \& Verona, 2012; Peters, Schneider, Griesshaber, \& Hoffmann, 2012), but remain blurry when it comes to services. Therefore, mapping the determinants of service innovation remains as a topic still to be addressed by researches.

To identify the determinants for innovation in services one should first focus on the dynamics of service innovation itself in order to establish what service components may be subject to innovation induction. After a couple of decades debating, first of all, the suitability of original industrial innovation theory to analyze innovation on services (and theory quickly learned that it did fill this gap); later, the appropriateness of using exclusive theoretical approaches to study innovation in service activities, recent authors have defended the integrated analysis of innovation for goods as for services (Droege, Hildebrand, \& Forcada, 2009; Morrar, 2014). Such approach has been named integrative and admits that innovation should be taken as a unique phenomenon for both industrial and service activities (Gallouj \& Weinstein, 1997; Gallouj \& Windrum, 2009), although particular service characteristics may impact the innovation's form of occurrence. But what services peculiarities should be taken into account to map a service innovation determinant and to what extent?

The service interaction is admitted to be the very constitutive element of services and consists of an exchange of competencies between the service provider and the client. It has gradually been recognized as a locus of innovation (Gallouj, 2002) and gained prominence among researches focusing on phenomena such as co-production or service encounters. Admitting that the interaction is a place for service innovation to occur highlights to active roles played by both provider and client. It allows us to take the client as an inductor of innovation by attributing to him the role of a market consumer, in accordance to the demand-pull approach (Kline \& Rosenberg, 1986). More than that, current literature on service innovation admits the client to act as a co-creator of value (Grönroos, 2011) whose readiness, technologization and connectivity affect the experience for service development (Verleye, 2015). While some works focus on explaining how clients act during service delivery to co-create innovation with service providers through measuring the customers' willingness to co-create (such as Handrich \& Heidenreich, 2013; Heidenreich \& Handrich, 2015), on this paper, we focus on the role played by the actors in charge of dealing with clients' inputs for innovation on service development. In this sense, we believe that the service provider also plays an active role as vector for innovation in mobilizing his personal and organizational skills to transform the prior customer's reality (Gadrey, 2000).

Provider's and client's roles as agents for innovation are well explored in the economics of innovation literature and have been transposed to the study of innovation in services. One peculiarity, however, draws our attention. In industrial activities, customers commonly act as sources of ideas for new products (or for improvement of existing ones) later taken to the producer's organization. The contributions of customers and producers are clearly defined and sequential, but such logic does not remain when it comes to services, where the service interaction represents not only the locus for innovation, but also the key to understand clients' and providers' roles on innovation. Thus, a customer feedback may change the provider's actions during the service interaction and vice-versa, emphasizing the dynamic and reformulative character of service delivery. 
The present research explores the reformulative nature of service provision (sometimes referred to as service delivery) as a result of the exchange and combination of competences (Gallouj \& Weinstein, 1997) from providers and clients to address the provider's role as a service innovation determinant (or vector). We explore the provider's role by admitting him to act as facilitator (or barrier, depending on his attitude) to the incorporation of suggestions and changes proposed by clients during the service interaction. Service providers have active roles on accepting, modifying or refusing changes on the service provision. We therefore assume that such particular attitude impacts the final service delivery as well as the generation of innovations. In this study, the willingness of the service provider to incorporate changes suggested by clients regarding the planned characteristics of service to be delivered constitutes a construct therefore referred as Willingness to Change in Services [WCS].

Establishing WCS as a construct leads to two questions: what is its nature? And what variables can explain it? Aiming to answer both questions, this paper aims to identify explicative dimensions for WCS and to develop and validate a measurement scale for it. To achieve such objective, we have selected Brazilian software development services as a research field due to its main characteristics. Software development industry refers to a wide scope of activities that include standardized ready-made software solutions, which resemble goods, as well as custom made software programs that are known to be highly specific to the particular needs of a client - software development services. Following the arguments of Steinmueller $(1995$, p. 3), we admit that a "particular software program that is only produced once should be viewed as a service output, while a program that is reproduced dozens or millions of times has development and marketing characteristics closer to those of manufactured goods". Such software programs are particularly valuable in terms of service research for three reasons: (a) they are delivered through well-defined development projects - therefore, they are very feasible for analysis; (b) demand high levels of customer involvement in its production; (c) it is common to have change of requirements from customers during service delivering (Staats, Brunner, \& Upton, 2011).

On second section, we describe the theoretical basis we have mobilized to propose the Willingness to Change in Services construct. On third section, we present the proceeding we have adopted to map the Explicative Dimensions for WCS through qualitative research. On fourth section, we present our definition for the idea of change in services. On fifth section, we describe the development and validation for our Willingness to Change in Services scale. Finally, on final section, we present our conclusions.

\section{Willingness to Change in Services: Theoretical Basis for the Construct}

There is a narrow connection between service activities and change. Such link has been accounted for since the introductory studies on services, such as Hill (1977), and has kept its place until present days. Hill's work constitutes one of the first attempts to analyze services as a provision process rather than as part of a sector. The author suggested that services constitute "a change in the condition of a person, or an asset belonging to an economic unit, which occurs as a result of an activity of another economic unit which willing accepts the first person or economic unit" (Hill, 1977, p. 318). This understanding of services as transformative of clients' conditions remained present on later works such as the service triangle by Delaunay and Gadrey (1987) in the later 1980's and kept its place on recent studies from the 2000's. Even though these authors have been adopting the term Service with "different meaning and connotation" (Lusch, Vargo, \& Tanniru, 2010, p. 19), they still refer to a process of using one's resources and competences to benefit another entity (Vargo \& Lusch, 2004). Despite of the change on theoretical approaches for analyses on services over past decades, the conception of a service as a transformative action - as a change provoking action - remained. But if services generate changes themselves, what does it mean to have change in a service?

The phenomenon here investigated - change in services - is part of the central dynamic that constitutes services: the co-production between a client and provider. It is a sine qua non condition for the provision of a service. Top works on service economy have been acknowledging the simultaneous consumption and production of a service as its very core feature over the past four decades on works 
from Hill (1977), Gadrey (2000), Miles (2005) and Rubalcaba (2007) among others. Co-production also means the locus for the occurrence of innovations (Gallouj, 2002) as the client's demands may correspond to a source of change. Such premise accounts for the demand-pull, a theoretical approach by Schmookler (1966) highly disseminated on contemporary service innovation theory.

Assuming that interaction between provider and client may be a source of innovation implies that limits established to this interaction would impact results in terms of innovation potential. Gallouj and Weinstein (1997) suggest that a service consists of a system of technical characteristics (material and immaterial) employed along with competencies from clients and providers in order to transform one's reality. Such premise reveals that service innovation results from a change on any of the service system's components - as long as it implies any form of improvement of final service, in accordance to Schumpeter' premise (Schumpeter, 1934). Therefore a service delivered by replicating a service system previously mobilized may be useful in terms of efficiency, but not for innovation. It's the case of frequently replicated services such as operations on A.T.M.s - highly efficient, but leaving no locus for any change.

An innovative service results either from a change in a previous service system or from the composition of an entirely new one (also a change in terms of what was offered before). Therefore, changes need to be made in the characteristics of a service to be delivered for innovation to occur. This change may arise from any of the components on the service system (Gallouj, 2002; Gallouj \& Weinstein, 1997) - clients, producers or technical characteristics. In this paper, we chose to examine the client's role as a desirable source of innovation and how Brazilian software development companies have been managing it. In order to do so, we investigated service providers' willingness to accept clients' suggestions on service delivery. As we have stated before, service providers act as facilitators or barriers to changes on a previously planned service design suggested by clients. It affects the co-production of service innovation emerging from clients' participation. It is noteworthy to say that change constitutes an innovation vector, meaning that the occurrence of change is a requisite for innovation to emerge. Both change and innovation share a dimension of action, given that the two phenomena refer, to a greater or lesser extent, to alterations in current situations. As change refers to an alteration of state, innovation refers to a successful change that led to meaningful results. In our context, we assume that changes occurring during the development of a software program are requisites for innovation.

Proposing and measuring WCS implies forming a theoretical basis for mapping change in services. Previous cited works have been helpful for comprehending the dynamics of service provision, but we lack understanding on the phenomenon of change itself. To constitute such theoretical base, studies investigating change in organizations and organizational changes have been taken into account. The work of Lau and Woodman (1995) has been highly disseminated due to its explanation of change as the difference between realities in the long-term. These authors stated that the occurrence of change consists on the opposite of innovation and its occurrence is not linked to the qualitative balance of its final result, limiting itself to changed conditions over time. Such understanding has contributed to the development of many explicative models for change in organizations, including the ones here taken into account as theoretical bases for measuring WCS.

Organizational change is currently a large field of study that aggregates researches from management, economics and psychology literature. In order to compose the theoretical basis for our construct, we have surveyed for top-cited references regarding organizational change on SAGE Journal on Line, JSTOR Arts \& Science I Collection, SpringerLink, Emerald Journals, Oxford Journals and Proquest. This literature review has been carried out on January 2012 by adopting change + organizational as keyword. We have considered papers published from 2005 to 2011 (five years). We have established as selection criteria for our paper: (a) presenting investigation on organizational change and (b) describing empirical researches.

In its seventh decade of production, literature has provided us with three highly disseminated theoretical models to explain organizational change (Demers, 2007). Such models are vastly cited and adopted as basis for a massive number of contemporary studies on organizational change. Burke and Litwin' model (1992) foresees effects created by organizational changes on individual, organizational 
and environmental levels; Robertson, Roberts and Porras' model (1993) explores impacts on individual and organizational levels; Greenwood and Hinings' model (1996) envisages impacts on organizational and environmental levels. Such models reveal the three levels recurrently accounted for: individual, organizational and environmental change. In this paper, we have brought those three levels to the context of change in services as a light for mapping the explicative dimensions for WCS.

\section{Mapping Explicative Dimensions for WCS}

In order to map explanatory dimensions for Willingness to Change in Services, we decided to carry on a large qualitative research with experts in software development services in Brazil. We have selected representatives from the Association for the Promotion of Excellence in Brazilian Software (Associação para Promoção da Excelência do Software Brasileiro [SOFTEX]) from every single region in the country as we intended to have a national study. We have conducted a large scope query with managers and representatives from top ten municipalities with the highest productivity in software development services in Brazil. In aggregate, such municipalities represent more than $90 \%$ of Brazilian production on software development services.

We adopted the mentioned methodological choice due to the exploratory nature of the WCS construct, which had no previous mapping. We follow recommendations from Pasquali (2010), who suggests that constructs in this condition should be surveyed by means of opinions from experts in the domain. Pasquali (2010) recommends interviews with individuals representing the aimed population to which the scale will target. In order to collect evidences, we have built three scripts for interviews. Each one of this scripts focused on one specific profile of respondents (one for the national manager of SOFTEX; one for the national innovation manager of SOFTEX; and one the ten regional managers from top ten software producing Brazilian cities).

We have conducted and analyzed the content of 19 face-to-face in depth interviews carried out with Brazilian software development service specialists on top ten software producing Brazilian cities (three specialists in Porto Alegre, one in Curitiba, two in Florianópolis, one in Brasilia, three in Rio de Janeiro, one in São Paulo, four in Belo Horizonte, one in Salvador and one in Recife). In aggregate, interviews have provided us 1,380 minutes. For content analysis, four thematic categories have been settled a priori: dynamics of client participation in software development; and the three dimensions associated with WCS on organizational; individual; and environmental levels.

For content analysis, we have simultaneously mobilized two functions associated to the content analysis: heuristics, focusing on enriching the exploratory attempts to interpret the contents, here based on the exploratory diagnostic of explicative dimensions for Willingness to Change in Services; and the function for proof test management, that allowed us to test the hypothesis of extension of the three levels of observation for the organizational change phenomenon (individual, organizational and environmental) to the phenomenon of change in services. The application of content analysis techniques in this study meets the recommendations from Bardin $(1998,2010)$ as being homogeneous, comprehensive, exclusive, objective and relevant.

Our four thematic categories defined a priori have guided our content analysis. We have analyzed every paragraph from the interviews records to identify thematic indicators that have led to the construction of our seven thematic dimensions that explain WCS. As our analysis intended to diagnose thematic indicators, we have not considered their frequency of appearance in the interviews records. Our thematic categories were built according to the recommendations of Flick (2009). The content analysis was performed by using manual techniques only. No auxiliary software has been used.

As we have not interviewed software development clients directly, we have considered our interviewees impressions on clients' perspectives. Analysis revealed the conditionals to the manifestation of WCS from software development specialists' point of view: client's capacity to supply 
service requirements and to interact with service provider; company's operational scope (customization or development); software's technical field of application; organization's interest in the end product to be developed; technical capacity and interpersonal abilities of developer. As for the WCS's dimensions, our analysis revealed the existence of seven of them, which are presented as follows.

The first dimension emerging from content analysis is Client relationship management and reveals four issues that impact WCS. First, it refers to the stages on software development that contain clients' participation. It varies significantly among developing companies and reveals the level of clientproducer interaction involved. Second, it addresses how organizations face client's roles and how useful they seem to find their participation on development. Interviews revealed that companies carry out two very distinct attitudes. Some companies "see the client as a partner" and therefore become "companies that are successful, victorious, clearly see that the client relationship is the most important thing they have. Nowadays, we see that this is what makes the whole difference". On the other hand, some companies take the client for "a necessary evil".

Third, it refers to how organizations manage their client's participation on software development. Interviewees revealed that the way companies decide to include their clients on software development impacts their production effectiveness, since experienced companies seem to have learned from previous experiences how to "work in an organized way" by "trying to tie down loose ends" and by demanding their clients to "approve the specifications (of the product)". Companies that don't have such experience are expected to face "a real problem". And fourth, the client's strategic importance also emerges. In order to meet client' needs, companies may increase their level of willingness to change: "some contracts are more advantageous, others are less so. Companies try to preserve their client relationship. They can even afford to incur some losses on some projects .... If you are more open to listen to suggestions and lose money over some issues, this will compensate somewhat".

Second WCS dimension to have emerged from analysis is Software characteristics and its development and refers to three particular issues. First, there are specificities of a contract such as availability of resources and targets deadlines; second, there is technical quality of the base software used by a company for its own service development. It may limit a company's level of adaptability to change regardless of willingness - sometimes, the background software simply prevents changes. Third, organizational interests and expectations on the final software solution may also affect the willingness to change as reveals this interviewee: "a company does this, financed by the company that is buying the product for the first time, since this is something they had in mind to develop themselves. It's a way to have financing".

The third dimension, Organizational conditions for change, emerged based on four main subjects. First one is organizational degree of openness to incorporate external knowledge and practices, commonly admitted to be more elevated on younger companies: "new companies with young management ... in terms of knowledge ... are more open minded when it comes to all that is new, the reasons for innovation, what is being created, what is emerging in the world". Second, support from the organizations also emerged as requisite for software developers to be willing to adopt changes. Third issue refers to organizational culture for change and reveals that some companies are more willing to accept changes than others. Fourth subject consists on the existence of rewarding mechanisms for collaborators who are most willing to accept changes: "when ... you are rewarded, there are outside incentives, ... (the individual) senses his work has been recognized, be it by bosses or otherwise", increasing the willingness to change.

Staff conditions compose the fourth dimension associated to WCS and comprehend two aspects. First one refers to how many simultaneous roles one individual has to play on a company. Interviewees showed the more distinct roles a single service provider has to carry out during software development, the less time he dedicates to each stage of it. Such condition also tends to reduce the level of client interaction during the process and the provider' willingness to accept changes in a service: "(the specialist) runs the risk of discussing issues less, since they have less time to do so". Second issue consists of the level of existing support between staff members. When the teams responsible for software development support the idea of incorporating a change, developers are more willing to accept such 
change: "when a company does not see itself as a team, it is more complicate to bring about change. They will always be gazing at their own navel".

Fifth dimension for WCS is composed by Administrative procedures and conditions for decision-making. It refers to limits imposed by administrative procedures on decision-making and on the willingness to change software projects. Interviewees revealed that companies with larger structures and greater number of hierarchal levels are less willing to change since "a larger (company) has standards to follow" and "when (a company creates) hierarchal levels ... they also create decisionmaking processes, ..., (which is when) they begin to create difficulties". Regarding the autonomy of technicians to make changes, interviewees underline that management systems used for controlling software development parameterize the process and take changes as points of inefficiency, therefore, something to be avoided.

Sixth dimension is Entrepreneurial behavior associated to individual or organizational levels. Interviewees showed that: "(regarding changes) many consider it as a challenge and like it. There are others who do not like it at all; they are the ones who are more settled in their ways. But these are few. ... These are the entrepreneurs, (who are) more competitive". Regarding software production, an entrepreneur is admitted to be "agile, always looking towards the future and seeing things from a wider perspective. Vision and creativity.... This person is someone who sees no problem in running risks or in undertaking new ventures that are somewhat uncertain", as accepting a change on a design service.

The seventh and last dimension associated to WCS is Interaction with supporting organizations. It admits that interaction between companies and supporting organizations exerts a positive impact on the organizational level of willing to accept changes, since "the more distant (specialists) are (from the external environment), and the less aptitude ... they show to up-date their knowledge, to improve their capacities, the more reactionary they become and they tend to react in a more radical way and do not accept innovation".

\section{Change in Services: Building a Definition}

Analysis carried out on interviews' content revealed how changes on a service design occur during service development process. This session presents such findings to map how changes occur as well as to build an understanding on what change on service means.

The statement "it is (just) a service. Therefore, ... no matter how well you present your specifications, you will always remain in the shadows. So, this area of shadows ..., within this grey zone, is where difficulties may arise" reveals a lack of certainty associated to the final product to be delivered by a service in progress. Although such uncertainty is taken for developers as "a natural part of life, (because) you sell one thing and deliver another, always", specialists point out that clients don't seem to share such understanding when it comes to altering a service design: "(the clients) believe that it is the same thing as acquiring an end product, which has certain characteristics. When we talk about services, it is a totally different matter". Theory confirms that software development services operate on significant degree of uncertainty since changes are common during production and may arise from customers, "from the underlying technology or external environment" (Staats et al., 2011, p. 377). Statements reveal disparities concerning how providers and clients face possible changes in the service to be delivered. While providers seem to expect that the final service may not correspond to what was designed at first, clients seem to keep their expectations for a final service consistent with the original service design, as argued by interviewees when questioned about how clients act during software development service.

Statements from interviewees, when asked about how clients act during service development, also bring evidences that clients have unclear expectations about the service they really expect when hiring a company to develop a software solution: "it is not very clear, even for the client, what it is that he 
needs. In this case, in this process of interaction, he (the service provider) is able to identify what the person requires. And this involves a whole process of interaction, and this is when he tries to get the client to specify exactly what it is that he needs". The very nature of service provision is taken as cause for this: "it is one thing to buy a finished product, you go there, buy a car, the car is all specified, that's the end of it. Other than finding some defect, you end up with the car. It is quite another thing if you order something about which you are not really very clear". Theory seems to corroborate such findings by recognizing the existence of a so called "service uncertainty" concerning uncertainty cause by lack of "quality of information flow and knowledge" (Erkoyuncu, Roy, Shehab, \& Cheruvu, 2011, p. 1223). Such statements bring evidences that clients are not always clear about what should be hired since the product of the service to be delivered is uncertain.

Statements also revealed that, when hiring a software solution, clients establish their expectations considering software programs or solutions they are familiar to: "clients do not have a vision of the possibilities that exist, because they only see this when these begin to materialize". It means that technological limits of the software solution a client already knows will shape his expectations regarding the software solution to be developed: "a client normally has a very day-to-day view of his problems. His vision does not have the capacity to extrapolate as, for example, permitting the use of related new technologies, new methodologies". Literature on services meets such statements by showing that clients seek transformation of a reality when hiring a service (Gershuny \& Miles, 1983), although their technical knowledge may be limited to the previous experiences they have had. It means clients' expectations on the software solution to be developed are shaped within the limits of their previously known software solution.

When it comes to software developers, expectations are shaped up very differently. The limits of knowledge of a developer do not perform the same function as for clients. Statements reveal that it is a common practice to accept projects that exceed a provider's current technical capacities since he expects to expand it on the occasion of developing a future software solution. Therefore, for developers, expectations regarding a service to be delivered are based on technical parameters (methodologies, functions, etc.) they believe they will be able to attend to. In short, we infer from interpreting our research interviews, developers shape their expectations for a software solution to be developed on technical parameters.

Although distinct in essence, client's and provider's expectations share a common point: their mutual uncertainty regarding the final service to be delivered. Clients initially expect the final service to meet their needs of reality altering within the limits of what they are familiar to in technological terms. Providers, in turn, analyze clients' demands and propose technical solutions to answer to it. In this very interaction, a client's initial expectations may change when facing suggestions from a provider. Once a service design is agreed to, both of them will expect the final service to correspond to their expectations. The disparity between clients' and providers' expectations becomes evident on this statement: "we already have companies that see far beyond the client. For example, they offer a client a cloud computing service, even though the client has no idea what this means, telling them that this can improve their business.... Companies are offering clients solutions that go way beyond their (the client's) limited vision, which are far beyond the problems they need to solve in their daily lives". These understanding on the software development process are summarized in Figure 1. 


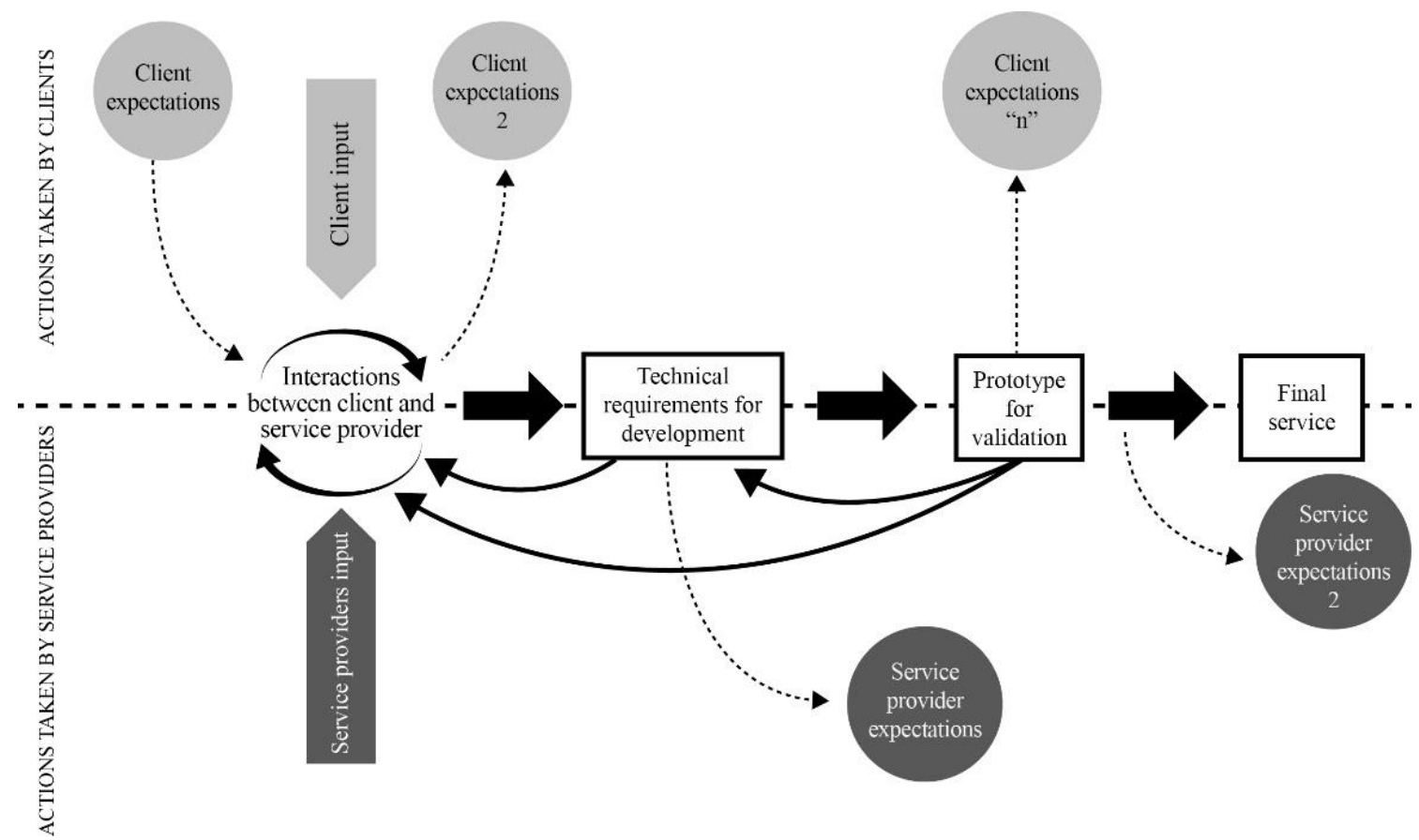

Figure 1. Process of Software Development Service

Stages shown in Figure 1 may be described according to the following stages. First, Client Expectations regarding the final product of a service are established in terms of reality altering before any interaction with the service provider occurs. Interaction occurs to transform Client Expectations in a solution based on technical parameters for the development of a software solution. At this time, the client provides suggestions, contributions and requirements (known as Client inputs) while the service provider adds his own suggestions (known as Service providers inputs). In result, Technical requirements for development are established.

After having established Technical requirements for development, Service provider expectations will arise based on technical parameters, deadlines, scope and cost. Those expectations involve developing the project as efficiently as possible - and this is where any change to the original project becomes a point of inefficiency. In order to meet the Technical requirements for development, a prototype is commonly developed to undergo client's approval. The testing of a prototype, in practice, has different meanings for developers and clients. As Technical requirements for development have been previously agreed to, providers tend to expect their clients to approve prototypes with no major questioning, but this is not the common outcome. As clients don't share provider's experience on software development, they expect the technical requirements to lead to a solution to their problems, but they can only be sure the software solution actually corresponds to what they expect by the time the prototype is ready to test. After testing it, clients are finally capable of experiencing a tangible solution for their reality altering demand and therefore their expectations for a Final service may be changed once more. Requests to change a Prototype go against the service provider's expectations - established in terms of deadlines and development costs. Thus, required changes carried out at this point will not only change the Final software solution, but will also generate new Service provider's expectations.

The described process reveals the dynamics of change on software development service. There are, at least, two changing points mapped for Client's expectations and one for Provider's expectations. As for Final service to be delivered, there are at least three mapped points of change. One should notice that stages presented on the model's main path may be recursive and imply on additional points of change. Mapping those multiple change patterns reveals that a track of change is the natural path for a service to be delivered under conditions of high interaction. As the client's and producer's expectations are dynamic and evolve during software delivering process, the software solution to be delivered is constantly reconfigured. This process also reveals a direct link between level of interaction 
and potential for changes and innovation in a service. We infer, from our research interviews, the higher the interaction on software developing process, the higher the chances of occurring changes on a service to be delivered, as the more intense the client participation is. But what does it imply for service management?

Although innovation is highly desired, change on planned specifications for a service does not face the same reaction from developers. As innovation is attached to qualitative improvement on software development - therefore highly desirable -, changes on a service design during development process represent threats to achieving previously stablished scope and cost objectives. Thus, management processes for service development elect service innovation as a goal to be achieved; but also elect changes on a service design as points of inefficiency to be avoided. This practice is highly contradictory. Change and innovation are partners (Poole \& Van de Ven, 2004), so change is actually a predictor for innovation. Companies may achieve great efficiency by delivering large-scale parameterized services (such as online check-in), but producing an innovative service requires them to have successful change in the characteristics of a service. Therefore, change in a service should be encouraged as an effort to achieve innovation. Such behavior is hereby defined as willingness to change in services (WCS) and corresponds to the willingness of an individual or organization to accept changes on a service design previously agree to.

In our research, we argue that WCS represents a predictor for innovation in software development services. In our qualitative research, we have carried out procedures to explain theoretical dimensions associated to WCS. Such effort allowed us to identify seven explicative dimensions associated to WCS - Client relationship management; Software characteristics and its development; Organizational conditions for change; Staff conditions; Administrative procedures and conditions for decision-making; Entrepreneurial behavior; Interaction with supporting organizations. We therefore admit that such dimensions predict the WCS construct. In the following research steps, we will present the development for a WCS scale by converting each dimension into variables to be tested in a sample of 351 companies. The structure in terms of explanatory dimensions, later to be converted into variables, is presented in Figure 2.

\section{Explicative Dimensions for WCS}

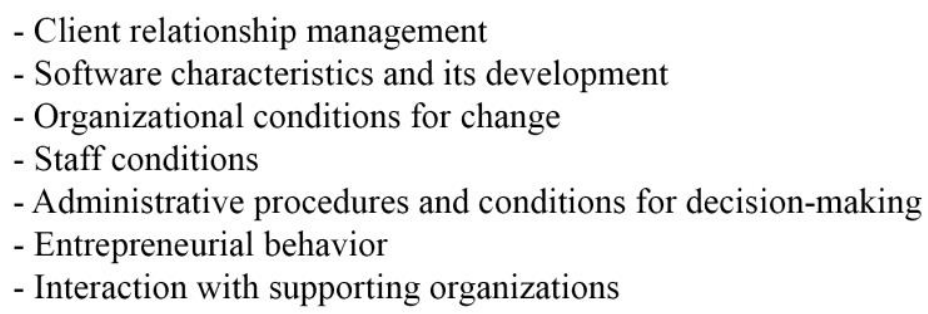

Figure 2. Explanatory Dimensions of WCS

\section{Development and Validation of Willingness to Change in Services Scale}

The seven dimensions associated to WCS lead to the proposition of 34 variables. We have considered the nature and constitution of each dimension to break it into representative variables later submitted to validation procedures. While transforming our seven explanatory dimensions into 34 variables, we have taken into account the level of complexity of the concepts associated to the construct and the fact that there is direct reciprocity between the targeted population and the construct complexity (Günther, 1999). As our population of respondents is highly familiarized to the dynamics of software development measured for the WCS construct we opted to elaborate a reduced number of items to be tested. 
Thus, the first version for the scale based on a single factorial structure arose. Such method has been chosen given the exploratory nature of WCS, that lacks factor retention validations from previous studies. The scale has been submitted to analysis of its theoretical relevance by a group of ten academic judges highly qualified on the fields of innovation, change and services. Judges have evaluated semantic quality and relevance for each item by means of a scale ranging from 1 to 5 , in which 1 represents very low, 2 represents low, 3 represents average, 4 represents good and 5 represents very good. The judges were finally invited to evaluate the scale as a whole as: (X) Adequate, (X) Partially Adequate or (X) Inadequate.

All of the ten judges considered the scale to be Adequate so they were able to proceed with an individual analysis for each variable. Taking into account ratings attributed by each judge for every item, a Validation of Content Coefficient (VCC) has been measured (Hernandéz-Nieto, 2002). VCC considers the average rating for each item according to the formula $M_{x}=\frac{\sum_{i=1}^{10} X_{i j}}{j}$, where $\mathbf{j}$ corresponds to the number of judges and $\boldsymbol{i}=\mathbf{1}$ represents the total ratings given by all of the judges. A $V C C_{i}$ has been estimated for each of the items on the scale by applying $V C C_{i}=\frac{M_{x}}{V_{\max }}$ and considering errors associated to the items by means of $P_{e_{i}}=\left(\frac{1}{j}\right)^{j}$. Finally, a VCC has been calculated for every item (so called $V C C_{c}$ ) using the formula $V C C_{c=}{ }_{C} C_{i}-P_{e_{i}}$.

Hernandéz-Nieto (2002) recommends that items with $V C C_{c}$ higher than 0.8 should be kept as part of a scale. Such parameter led to the elimination of two items on our scale. Five additional items have been eliminated since judges recognized them to be in duplicity to other items from the scale. Still under judges' recommendations, one item has been split into two and two other items have been grouped into a single one. Remaining items underwent minor adjustments suggested by the judges. An intermediary version for the scale arose from such proceedings. It was composed of 27 items. It has been submitted to semantic validation with seven software production specialists matching the expected technical profile for future respondents on the survey to be carried out. Such procedures led to changes on three items on the scale and to the elimination of one item for being considered inconsistent with market practices on the sector. The remaining 26 items formed the WCS scale finally applied on our survey. Table 1 shows WCS scale's items.

Table 1

\section{WCS Scale Applied on Survey}

\section{In our company...}

1. There are different ways to describe system prototypes to incorporate client suggestions.

2. Our priority is to guarantee that the software developed adheres to its original specifications.

3. The client is free to suggest changes during the software approval phase.

4. Technical members of our staff who are more willing to accept client suggestions for changes in software requirements are rewarded.

5. Client suggestions that change the original project are more easily acceptable when involving a software solution that has the potential to generate advances in existing technology.

6. We believe that cooperating with other companies makes our own company more willing to accept client suggestions for changes in software programs.

7. We have adopted standards to improve our software development process (such as Mps.Br / CMMI / COBIT / ITIL, amongst others). 


\section{Table 1 (continued)}

In our company...

8. We incorporate client suggestions that change an original software project irrespective of its development schedule.

9. Members of our technical staff are encouraged to accept changes suggested by clients on original software projects.

10. Client suggestions that change original projects are more acceptable for a software solution that presents greater potential for sale to other clients.

11. The many functions carried out by our professional staff responsible for software development make it more difficult to accept client suggestions for changes to an original software project.

12. Our professional staff is free to accept client suggestions for changes to an original software project.

13. Client participation in software development makes it easier to carry out the project.

14. Client suggestions that change an original project are more acceptable for a software solution that presents greater profit margin.

15. We are open to suggestions from clients to make changes to software solutions.

16. Management supports changes suggested by clients regarding an original software solution.

17. Changes to software development suggested by major clients are more acceptable compared to similar requests from other clients.

18. We believe that changes incorporated into software solutions will make a difference in the future.

19. Client participation in software development occurs in phases other than software specification.

20. We aim to reduce client participation related to changes to an original software project.

21. Our technicians are willing to incorporate client suggestions for changes to a software solution.

22. We believe that client suggestions help improve the quality of the software we develop.

23. We accept the risks involved in changing an original software project.

24. We incorporate client suggestions to change an original software project irrespective of its stage of development.

25. Client suggestions that change an original project are more acceptable when these involve software that has the potential to generate gains for society.

26. People from our staff support each other so as to incorporate software changes suggested by clients.

Willingness to Change in Service scale has been applied on a survey carried out in 2012 on a random sampling of 351 software development companies in Brazil. This sample is composed of companies that provide software development services with high interaction between client and service providers (mainly software development or customization). 18 regional agents from SOFTEX have collaborated to mobilize companies to answer to our research. They have provided us a database of 897 companies linked to SOFTEX across the country. We chose to extend this number with the incorporation of a second database of software companies associated to Brazilian Association of Software Companies (Associação Brasileira das Empresas de Software [ABES]), comprised of 1216 companies, and the base of Association of Brazilian Companies for Information Technology (Federação das Associações das Empresas Brasileiras de Tecnologia da Informação [ASSESPRO]), consisting of approximately 200 companies. By aggregating the tree mentioned databases, we have composed our own national database formed by 2,300 companies.

The original scale has been written and applied to respondents in Brazilian Portuguese. Translation into English has been provided for the publication of the present work. We selected companies that provided highly interactive services on demand to order or customized software solutions to make sure the phenomenon of willing to change could be present. In each company, an information technology expert has been selected to participate on the survey. Companies have been contacted via telephone and questionnaires have been filled on real time follow-up. A Likert scale of ten points (where 1 means strongly disagree and 10 means strongly agree) has been applied to measuring WCS items. Likert scale is the most common option for studies on psychological subjects. As WCS 
consists of a construct occurring on psychological level as well as on organizational and environmental levels, we selected the Likert scale to attend to our purpose of properly measuring a psychological subject (Günther, 1999). We opted for a 10 points scale in opposition to the traditional five points scale to increase the power of our measure by providing more variance among answers.

Our sample consisted of 351 companies developing highly interactive software development services in Brazil. Such companies are distributed as follows: 195 companies in the southeast region; 85 in the south; 41 in the north and northeast; and 27 in the central-west region. Regarding their market experience, companies have been operating, in average, for 14 years. Standard deviation for experience on the market reaches 7 years. $25 \%$ of our companies have been on operation for up to 8 years; $50 \%$ up to 14 years; and $75 \%$ up to 20 years. Regarding number of employees, $30 \%$ of the companies in our sample employ up to 12 employees; $50 \%$ up to 25 employees and $80 \%$ up to 80 people. Only 18 companies in our sample employ over 300 people.

Data obtained from survey has gone through an Exploratory Structural Equation Modeling (ESEM) analysis in order to statistically validate the scale. For the WCS factorial structure analysis, Kaiser-Meyer-Olkin (KMO) and Bartlett's test have been used to measure common variance regarding to the sampling's set of variables. The tests indicate if variables may be attributed to a factor. Tests' parameters admit that the closer an output gets to 1 (KMO > 0,5 is the minimum limit allowed), the more favorable it is to apply factorial analysis to the data. WCS' KMO score is 0,8 , so factorial analysis seems to be appropriate for the data. Bartlett explored the existence of a desirable correlation between variables on data set by testing the null hypothesis that data's distribution would fit a matrix identity with no significant correlation. For WCS, the null hypothesis with a value of 2463.928 for the Chisquare $\left(X^{2}\right)$ has been rejected, meaning that it would be appropriate to carry out a factorial analysis on the sampling data. More than that, all individual items KMO, measured by the anti-image correlation matrix (Field, 2005), presented values higher than 0.5 , which suggests adequacy of all items to the scale. The minimum value was found to item 2 (0.661) whereas the highest value was found to item $18(0.899)$.

Initially, we sought to determine the number of factors to be associated to WCS scale. As the construct had never been previously tested and there was no factorial structure validated for the construct, we based our factor association on statistical procedures. A Principal Components Analysis has been carried out using the Oblimin rotation method in SPSS. It revealed seven factors with eigenvalues $>1$ (parameter to constitute factors). This high number, however, was not confirmed by the scree-plot analysis, which suggested three factors as being a more representative way to distribute the data, since one factor had an eigenvalue higher than 5 and two factors had values higher than 2 .

To support the emerging factorial structure, we have sought to adopt robust statistical procedures by carrying out an alternative Principal Components Analysis using Factor software. We also run and a Parallel Analysis with factorial retention in a polychromic correlation matrix (Timmerman \& LorenzoSeva, 2011). It consists of a Monte-Carlo simulation procedure for indicating the number of factors to be retained by using a high number of random repeated samplings (we adopted criteria of 1000 (DeVellis, 2012) repeated sub-samplings for this study). As sample error is dramatically reduced on such procedure, it is acknowledged to be among most reliable methods for factor retention analysis (Hayton, Allen, \& Scarpello, 2004). New Principal Components Analysis actually supported the structure of three factors for WCS (marked by *), as shown in Table 2. 
Table 2

Analysis of Principal Components for the WCS

\begin{tabular}{cccc}
\hline & Variable Real-data & Mean of random & 95 percentile of random \\
\hline 1 & $6.51242^{*}$ & 1.53635 & 1.61941 \\
\hline 2 & $2.53363^{*}$ & 1.45156 & 1.50794 \\
\hline 3 & $2.17973^{*}$ & 1.39171 & 1.44138 \\
\hline 4 & 1.27474 & 1.33659 & 1.38330 \\
\hline
\end{tabular}

Note. Source: Research data.

*Advised number of dimensions: 3.

Having settled the best factorial retention for WCS as being composed by three factors, we proceeded to run a Factorial Analysis on our sampling data. As WCS scale had never been tested before, we had no previous empirical experience to compare our results to. It is noteworthy to remember, however, that this scale has been composed from dimensions emerging from our own empirical findings from qualitative evidences collected on interviews records. Even though our WCS scale was considered exploratory as it had not been previously tested, we relied on our empirical evidences as well as on theoretical basis to build it.

Regarding our statistical choices, we adopted a conservative approach considering the exploratory nature of WCS scale. For studies testing the development of new constructs, Exploratory Factorial Analysis (EFA) could incorrectly lead to the elimination of a significant number of variables, so it led us not to explore the usual EFA followed by Confirmatory Factorial Analysis (CFA).

Although we have opted for not using EFA in our factor analysis, we maintained our purpose of seeking for a robust statistical technique that could properly fit our data. We have decided to carry out an analysis capable of indicating adjustment indexes for WCS' variables. An Exploratory Structural Equation Modeling (ESEM) analysis was therefore run on our data. Such technique is recommended as alternative or complimentary to EFA and presents Goodness-of-fit indexes (Asparouhov \& Muthén, 2009). The ESEM is an exploratory factor analysis technique which aims to evaluate the factor structure of measures with an additional feature of informing goodness-of-fit indexes to the model. We also used Weighted Least Squares Mean and Variance - Adjusted (WLSMV) estimation method as it is specially designed for polytomous data and incorporates categorical response variables (Muthén \& Muthén, 2010). For factorial rotation we have used an oblique Geomin method allowing correlations to be made between the factors. In order to evaluate the factorial structure of WCS in the ESEM analysis, the following adjustment indexes and evaluation parameters have been used:

Table 3

Indexes, Reference Parameters and Values for WCS on ESEM Analysis

\begin{tabular}{llc}
\hline Index & Reference Parameter & WCS \\
\hline Chi-squared for degrees of freedom $\left(\mathrm{X}^{2} / \mathrm{gl}\right)$ & $\mathrm{X}^{2} / \mathrm{gl}<3$ indicates sampling adjusted models. & 2.07 \\
\hline Comparative fit index $(\mathrm{CFI})$ & $\mathrm{CFI}>0.90$ is desirable. & .93 \\
\hline Tucker-Lewis Index $(\mathrm{TLI})$ & $\mathrm{TLI}>0.90$ is desirable. & .90 \\
\hline Standardized Root-Mean Residual $(\mathrm{SRMR})$ & SRMR $<0.010$ shows adequate residual levels. & 0.053 \\
\hline
\end{tabular}

Note. Source: Research data.

$\mathrm{X}^{2} / \mathrm{gl}$ WCS' score is 2.07. It is considered favorable as well as CFI and TLI (.93 and .90, respectively). SRMR score for WCS is 0.053 . It does not compromise the quality of the factorial 
structure if all of four indexes are analyzed together. An addition test has been run to determine the factors' reliability. Cronbach's Alphas have been calculated for each factor. Obtained scores are: Factor 1: 0.8; Factor 2: 0.65; Factor 3: 0.73. Given the exploratory nature of WCS construct, we opted not to eliminate Factor II even though its Cronbach's Alphas have not reached minimum parameter of 0.7. We present our factorial structure assigned to WCS according to ESEM analysis on Table 4.

Table 4

Initial Factorial Structure for WCS According to ESEM Analysis

\begin{tabular}{cccc}
\hline Items & Factor I & Factor II & Factor III \\
\hline Cronbach's Alpha & $\mathbf{0 . 8}$ & $\mathbf{0 . 6 5}$ & $\mathbf{0 . 7 3}$ \\
\hline V1 & 0.440 & -0.041 & -0.262 \\
V2 & 0.328 & -0.235 & -0.125 \\
V3 & 0.510 & 0.274 & -0.148 \\
V4 & 0.054 & 0.350 & 0.195 \\
V5 & 0.362 & 0.027 & 0.438 \\
V6 & 0.601 & -0.008 & 0.130 \\
V7 & 0.282 & -0.122 & -0.012 \\
V8 & 0.015 & 0.544 & 0.314 \\
V9 & 0.360 & 0.618 & -0.012 \\
V10 & 0.015 & 0.178 & 0.816 \\
V11 & 0.240 & -0.305 & 0.270 \\
V12 & -0.057 & 0.565 & 0.256 \\
V13 & 0.636 & -0.068 & 0.084 \\
V14 & 0.100 & -0.032 & 0.761 \\
V15 & 0.859 & 0.028 & -0.026 \\
V16 & 0.685 & 0.171 & 0.054 \\
V17 & -0.104 & -0.084 & 0.577 \\
V18 & 0.659 & -0.095 & 0.251 \\
V19 & 0.203 & 0.479 & -0.129 \\
V20 & -0.532 & -0.001 & 0.377 \\
V21 & 0.208 & 0.478 & 0.021 \\
V22 & 0.728 & -0.011 & 0.097 \\
V23 & 0.424 & 0.063 & -0.133 \\
V24 & -0.050 & 0.439 & 0.318 \\
V25 & 0.276 & 0.094 & 0.185 \\
V26 & 0.506 & 0.098 & 0.250 \\
\hline
\end{tabular}

Note. Source: Research data

We have analyzed factorial load for every variable on our scale relative to each factor. We admitted as parameter a minimum of 0.3 to accept a variable since we tested a construct for the very first time. Given their low factorial loads, V7 and V25 were eliminated from our scale. Remaining 24 variables, which have been kept in the factorial structure. Four variables presented cross loadings in more than one factor (V5, V8, V9 e V24). Analysis carried out on such variables revealed that V5 and V9 really scored their best theoretical representativeness on those factors where they showed higher factorial loads (Factor III and Factor II, respectively). V5 and V9 have been kept assigned to these factors. V8 and V24 presented greater factorial load for Factor II, although they had cross loading for Factor III. Analysis on these variables revealed they scored better theoretical consistency on Factor III, so they have been repositioned on it. Having V8 and V24's repositions to Factor III and the elimination 
of V7 and V25, a new ESEM analysis was run. Results reveal an adjusted factorial structure for WCS as presented on Table 5 .

Table 5

Adjusted Factorial Structure for WCS in ESEM Analysis

\begin{tabular}{cccc}
\hline Items & Factor I & Factor II & Factor III \\
\hline Cronbach's Alpha & $\mathbf{0 . 8}$ & $\mathbf{0 . 5 7}$ & $\mathbf{0 . 6 9}$ \\
\hline V1 & 0.434 & -0.035 & -0.294 \\
V2 & 0.318 & -0.225 & -0.156 \\
V3 & 0.527 & 0.273 & -0.168 \\
V4 & 0.056 & 0.349 & 0.205 \\
V5 & 0.378 & 0.020 & 0.411 \\
V6 & 0.622 & -0.015 & 0.089 \\
V8 & 0.013 & 0.553 & 0.343 \\
V9 & 0.369 & 0.621 & -0.007 \\
V10 & 0.033 & 0.165 & 0.816 \\
V11 & 0.244 & -0.309 & 0.235 \\
V12 & -0.051 & 0.564 & 0.286 \\
V13 & 0.651 & -0.080 & 0.027 \\
V14 & 0.119 & -0.046 & 0.746 \\
V15 & 0.876 & 0.018 & -0.089 \\
V16 & 0.711 & 0.163 & 0.014 \\
V17 & -0.097 & -0.091 & 0.575 \\
V18 & 0.686 & -0.113 & 0.195 \\
V19 & 0.202 & 0.484 & -0.120 \\
V20 & -0.544 & 0.002 & 0.414 \\
V21 & 0.219 & 0.470 & 0.024 \\
V22 & 0.749 & -0.034 & 0.026 \\
V23 & 0.437 & 0.043 & -0.176 \\
V24 & -0.035 & 0.430 & 0.339 \\
V26 & 0.512 & 0.084 & 0.202 \\
\hline
\end{tabular}

Note. Source: Research data

Removal of variables V7 and V25 led to some changes on the adjustment indexes for the new factorial structure. $\mathrm{X}^{2} / \mathrm{gl}$ 's score remained below the upper limit of 3. CFI and TLI's scores have been improved in comparison to the previous structure (CFI went from 0.93 to 0.94 and TLI went from 0.9 to 0.92 ). SRMR went from 0.053 to 0.050 , revealing improvement comparing to previous structure. In addition, new reliability tests for WCS factors were run considering Cronbach's Alpha. Factor I's score has been kept unaltered at 0.8 as no alteration occurred on it. Score for Factor II actually reduced from 0.65 to 0.57 . It means it kept under minimum parameter of 0.7 to be considered acceptable. It may indicate that factorial structure assigned for Factor II may require future tests on new samples as to improve its reliability.

Although Cronbach's Alphas for Factors II and III have suffered reductions in the new factorial structure, we decided to maintain it due to the improvements on the goodness-of-fit indexes. Following the recommendations of Damásio (2012) to evaluate the reliability of our factorial structure, we do not exclusively rely on Cronbach's Alpha to decide it. As factors with small numbers of variables are known to lead to decreases in Cronbach's Alpha (Cortina, 1993) such as Factors II and III), we decided to consider this parameter in association to the three others provided on our ESEM (CFI, TLI and SMRM). 
In this sense, we adopted Cronbach's Alpha as one out of four indexes to decide the factorial structure to be retained. Although our Cronbach's Alphas for factors II and III have been reduced in the new factorial structure, CFI improved in 0.01; TLI improved in 0.02; and SRMR improved in 0.003. As three out of four parameters (CFI, TLI and SMRM) were improved, despite reductions on Cronbach's Alpha, we decided to retain this factorial structure. Our decision to retain a factorial structure that presents reduced Cronbach's Alphas meets the recommendations for researches using ESEM as we opt to rely on a combination of indexes rather than solely considering Cronbach's Alphas. Recent researches adopting ESEM (such as Marsh et al., 2010; and Marsh et al., 2011) have followed a similar approach.

After having established WCS' factorial structure and variables assigned to each of its three factors, we proceeded to develop theoretical constitutive definitions for each factor. Variables V1, V2, V3, V6, V13, V15, V16, V18, V20, V22, V23 and V26 have been assigned to Factor I (as shown on Table 1). The analysis of the theoretical nature on those variables reveals they share two common conceptual nucleons. Variables V1, V16, V20 and V26 refer to organizational routines, a concept explored in organizational literature on discussions on organizational behavior, limited rationality and innovation. Organizational routines consist of repetitive processing of information shared by groups of individuals functioning as units on complex interaction patterns (Salvato \& Rerup, 2010) admitted to drive organizational performance (Felin \& Foss, 2009).

Variables V2, V3, V6, V13, V15, V18, V22 and V23 are also assigned to Factor 1, but refer to organizational principles and beliefs shared between individuals. These elements make reference to the concept of organizational values, foundational building blocks of for organizational culture (Khazanchi, Lewis, \& Boyer, 2007) that inform structures of belief and reinforce daily practices on organizations (Higgins \& McAllaster, 2002). Factor is therefore understood to be formed by Organizational Routines and Values. As both routines and values are considered a building part for organizational culture, theoretical resemblance among variables on Factor I is no surprise at all.

Variables assigned to Factor II are V4, V9, V11, V12, V19 and V21 (as shown on Table 1). Theoretical analyses revealed they relate to the common conceptual nucleon Organizational Structure for Change. Such structure is admitted to result from both tacit and explicit actions. Tacit ones refer to non-formalized encouragement given by organizations for its employees to accept changes. Explicit actions from an organization refer to explicitly rewarding those who accept changes. Organizational structure for change also results from favorable working conditions on organizations, here admitted as: reduced number of simultaneous functions performed by professionals; raise on levels of autonomy for staff members; and increased levels of interaction with clients.

Variables assigned for Factor III are V5, V8, V10, V14, V17 and V24 (as shown on Table 1) and may also be grouped into one common conceptual nucleon. V5 and V10 indicate the characteristics of software while V8, V14 and V24 refer to aspects of software development process such as deadlines or profit margins. Finally, V17 refers to the clients for whom software is being developed for. Considering the theoretical nature of its assigned variables, Factor III is denominated Service Specificities. Factorial structure for WCS and variables assigned to each of its three factors are presented in Figure 3. 


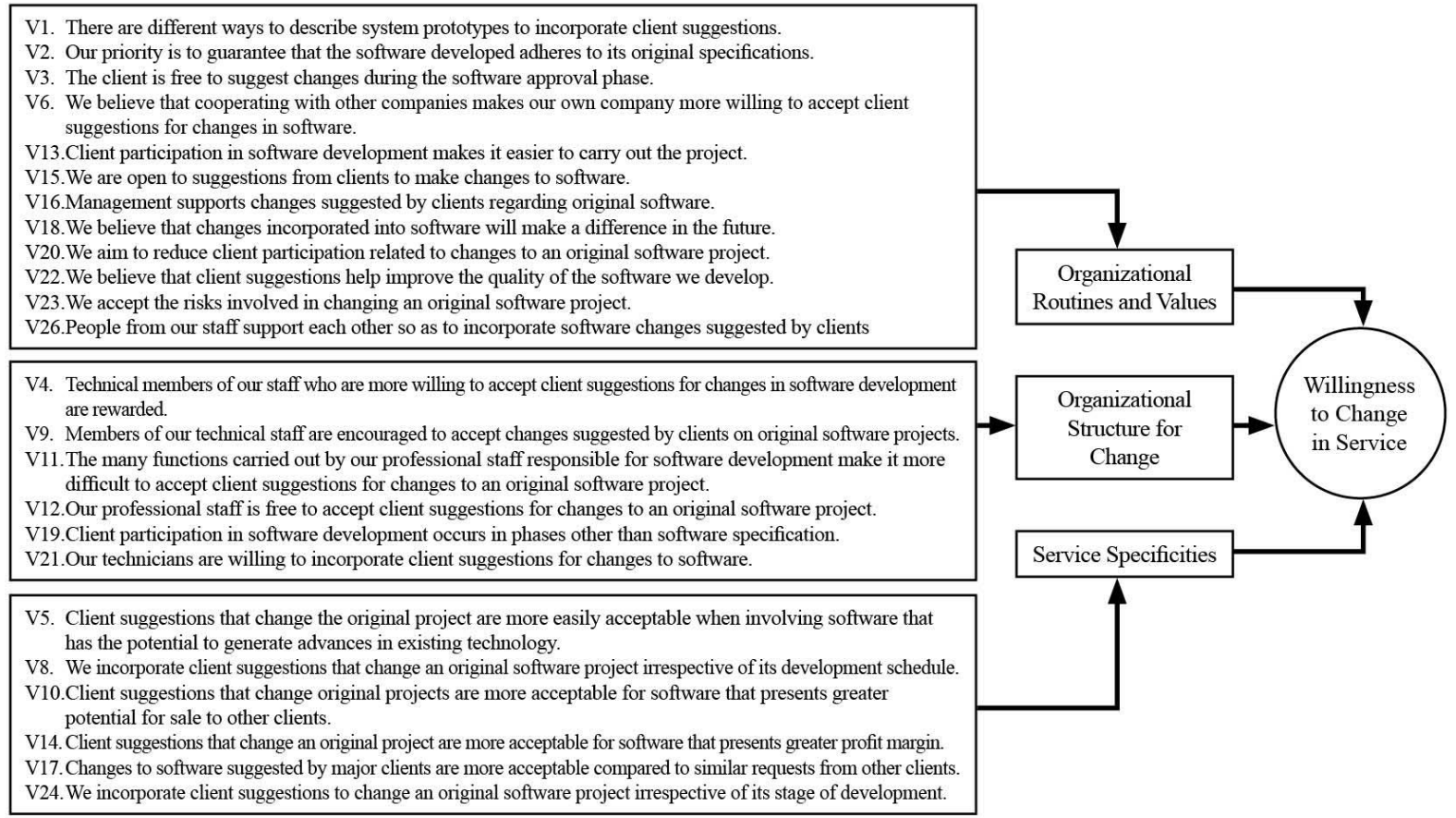

Figure 3. Factorial Structure and Variables on WCS Construct

\section{Conclusions}

This study explored a phenomenon occurring on software development service provision hereby admitted to be a service innovation determinant. It consists of the willingness of service providers to incorporate changes suggested by clients altering previously planned services during its development. We address to such innovation determinant as a construct referred to as Willingness to Change in Services [WCS]. We have mapped seven explicative dimensions for WCS: Client relationship management; Organizational conditions for change; Software characteristics and development; Conditions affecting the teams; Administrative procedures and decision-making conditions; Entrepreneurial behavior; Interaction with supporting organizations.

The seven dimensions have generated a scale initially composed of 34 variables. Theoretical and semantic procedures have led scale to be reduced to 26 variables later submitted to a large survey carried out with 351 typical Brazilian software development service companies operating all over the country. Data from our sample have been submitted to multivariate statistical analysis to provide validation for the WCS scale. After factorial analysis procedures, 24 items have been validated and assigned to three factors representative of WCS: Organizational Routines and Values - 12 variables; Organizational Structure for Change -6 variables; and Service Specificities -6 variables.

Factorial structure assigned to WCS allowed the construct to achieve satisfactory indexes for Chisquared for degrees of freedom, as WCS' $\mathrm{X}^{2} / \mathrm{gl}$ score is placed below the upper limit of 3 . Comparative fit index (CFI) for WCS is 0.93 and Tucker-Lewis Index (TLI) is 0.92 , both being $>0.90$ (desirable parameter). Standardized Root-Mean Residual (SRMR) for WCS is 0.053, meeting the advised parameter (SRMR < 0.010). Cronbach's Alphas for WCS's factors are: Factor $1-0.8$; Factor $2-0.57$; Factor $3-0.69$ (on the limit of parameter recommending it to be higher than 0.7). It means two of WCS' factors showed to be sufficiently well established. The third factor is slightly below parameter's limit, but has been kept assigned to the construct considering this was the very first attempt at measuring its variables. We expect future uses of WCS scale will be able to provide further tests on its factorial structure. 
Among limitations affecting the present study, one should point out the effects of working with an exploratory construct. The fact that WCS is based on an entirely new measurement scale prevents us from considering previous tests on its factorial structure meaning that applying traditional methods for EFA could lead to wrongfully eliminate variables. Further research will be able to test a previously validated version of WCS scale, allowing the use of EFA and CFA. The choice of one service sector to use as case for the development of the WCS scale may also be highlighted as a limitation on the present study. We hope further researches to be able to extent surveys based on WCS scale for additional service sectors.

We expect our study to be able to provide a theoretical contribution by shedding light into the connection between change and innovation. Although innovation theory is aware that change and innovation are partners (Poole \& Van de Ven, 2004), the operationalization of their relation remained undertheorized. As WCS scale establishes change as a vector for innovations in software development services and provides an operationalization to its measure, we expect future research will be able to test this connection to bring further theoretical advances. We would also like to state possible managerial contributions to derive from our study. While innovation relates to a process of change that generates gain, change in services does not necessarily provide better results for a service in qualitative terms. Thus, increasing a firm's WCS may lead to modifications on the original design planned for a software in development service, but there is no guarantee that it will provide gains in terms of innovation. It means managers should pay attention to the way both firm and employees manifest their WCS through organizational and individual behaviours associated to factors on WCS, but should not ignore the fact that risk is a constant variable attached to the conversion of change into innovation.

We expect this research to have contributed to service innovation literature by providing empirical and statistical evidences from a large scale survey mapping a service innovation determinant. We look forward for our current limitations to be addressed as research agenda for the field. Thus we present two new research queries to be explored by fellow researchers: would results from our sample be also observable on alternative service activities? and would WCS's organizational score be an efficient predictor of organizational innovation performance in both service and goods firms, as integrative approach would lead us to assume?.

\section{Acknowledgments}

This research has received funding from the CAPES-COFECUB Program.

\section{References}

Asparouhov, T., \& Muthén, B. (2009). Exploratory structural equation modeling. Structural Equation Modeling, 16(3), 397-438. http://dx.doi.org/10.1080/10705510903008204

Bardin, L. (1998). L'analyse de contenu (9e éd.). Paris: PUF.

Bardin, L. (2010). Análise de conteúdo. Lisboa: Edições 70.

Buera, F. J., \& Kaboski, J. P. (2012). Scale and the origins of structural change. Journal of Economic Theory, 147(2), 684-712. http://dx.doi.org/10.1016/j.jet.2010.11.007

Burke, W., \& Litwin, G. (1992). A causal model of organizational performance \& change. Journal of Management, 18(3), 523-545. http://dx.doi.org/10.1177/014920639201800306 
Cainelli, G., Evangelista, R., \& Savona, M. (2006). Innovation and economic performance in services: a firm-level analysis. Cambridge Journal of Economics, 30(3), 435-458. http://dx.doi.org/10.1093/cje/bei067

Cortina, J. M. (1993). What is coefficient alpha? An examination of theory and applications. Journal of Applied Psychology, 78(1), 98-104. http://dx.doi.org/10.1037/0021-9010.78.1.98

Damásio, B. F. (2012). Uso da análise fatorial exploratória em psicologia. Avaliação Psicológica, 11(2), 213-228. Retrieved from http://pepsic.bvsalud.org/pdf/avp/v11n2/v11n2a07.pdf

Delaunay, J. C., \& Gadrey, J. (1987). Les enjeux de la societé de service. Paris: Presses de la Fondation Nationale des Sciences Politiques.

Demers, C. (2007). Organizational change theories. Los Angeles, USA: Sage Publications.

DeVellis, R. F. (2012). Scale development: theory and applications (Vol. 26). New York: Sage Publications.

Di Stefano, G., Gambardella, A., \& Verona, G. (2012). Technology push and demand pull perspectives in innovation studies: current findings and future research directions. Research Policy, 41(8), 1283-1295. http://dx.doi.org/10.1016/j.respol.2012.03.021

Droege, H., Hildebrand, D., \& Forcada, M. A. H. (2009). Innovation in services: present findings, and future pathways. Journal of Service Management, 20(2), 131-155. http://dx.doi.org/10.1108/09564230910952744

Erkoyuncu, J. A., Roy, R., Shehab, E., \& Cheruvu, K. (2011). Understanding service uncertainties in industrial product-service system cost estimation. The International Journal of Advanced Manufacturing Technology, 52(9), 1223-1238. http://dx.doi.org/10.1007/s00170-010-2767-3

Felin, T., \& Foss, N. J. (2009). Organizational routines and capabilities: historical drift and a coursecorrection toward microfoundations. Scandinavian Journal of Management, 25(2), 157-167. http://dx.doi.org/10.1016/j.scaman.2009.02.003

Field, A. (2005). Discovering statistics using SPSS (2nd Ed.). London: Sage.

Flick, U. (2009). An introduction to qualitative research. London: Sage.

Gadrey, J. (2000). The characterization of goods and services: an alternative approach. Review of Income and Wealth, 46(3), 369-387. http://dx.doi.org/10.1111/j.1475-4991.2000.tb00848.x

Gallouj, F. (2002). Innovation in the service economy: the new wealth of nations. Cheltenham: Edward Elgar.

Gallouj, F., \& Savona, M. (2009). Innovation in services: a review of the debate and a research agenda. Journal of Evolutionary Economics, 19(2), 149-172. http://dx.doi.org/10.1007/s00191-008-01264

Gallouj, F., \& Weinstein, O. (1997). Innovation in services. Research Policy, 26(4), 537-556. http://dx.doi.org/10.1016/S0048-7333(97)00030-9

Gallouj, F., \& Windrum, P. (2009). Services and services innovation. Journal of Evolutionary Economics, 19, 141-148. http://dx.doi.org/10.1007/s00191-008-0123-7

Gershuny, I., \& Miles, I. (1983). The new service economy - the transformation of employment in industrial societies. London: Frances Pinter Publishers. 
Greenwood, R., \& Hinings, C. (1996). Understanding radical organizational change: bringing together the old \& the new institutionalism. Academy of Management Review, 21(4), 1022-1054. http://dx.doi.org/10.5465/AMR.1996.9704071862

Grönroos, C. (2011). Value co-creation in service logic: a critical analysis. Marketing Theory, 11(3), 279-301. http://dx.doi.org/10.1177/1470593111408177

Günther, H. (1999). Como elaborar um questionário. In L. Pasquali (Ed.), Instrumentos psicológicos: manual prático de elaboração (pp. 231-258). Brasília, DF: UnB, LabPAM/IBAPP.

Handrich, M., \& Heidenreich, S. (2013). The willingness of a customer to co-create innovative, technology-based services: conceptualisation and measurement. International Journal of Innovation Management, 17(04), 1350011. http://dx.doi.org/10.1142/S1363919613500114

Hayton, J., Allen, D., \& Scarpello, V. (2004). Factor retention decisions in exploratory factor analysis: a tutorial on parallel analysis. Organizational Research Methods, 7(2), 191-207. http://dx.doi.org/10.1177/1094428104263675

Heidenreich, S., \& Handrich, M. (2015). Adoption of technology-based services: the role of customers' willingness to co-create. Journal of Service Management, 26(1), 44-71. http://dx.doi.org/10.1108/JOSM-03-2014-0079

Hernandéz-Nieto, R. A. (2002). Contribuicions al análisis estatístico. Mérida: Universidad de Los Andes/IESINFO.

Higgins, J. M., \& McAllaster, C. R. A. I. G. (2002). Want innovation? Then use cultural artifacts that support it. Organizational Dynamics, 31(1), 74-84. Retrieved from http://connection.ebscohost.com/c/articles/7343705/want-innovation-then-use-cultural-artifactsthat-support-it

Hill, T. P. (1977). On goods \& services. Review of Income \& Wealth, 23(4), 315-338. http://dx.doi.org/10.1111/j.1475-4991.1977.tb00021.x

Khazanchi, S., Lewis, M. W., \& Boyer, K. K. (2007). Innovation-supportive culture: the impact of organizational values on process innovation. Journal of Operations Management, 25(4), 871-884. http://dx.doi.org/10.1016/j.jom.2006.08.003

Kim, J., Lee, S., Geum, Y., \& Park, Y. (2012). Patterns of innovation in digital content services: the case of App Store applications. Innovation, 14(4), 540-556. http://dx.doi.org/10.5172/impp.2012.14.4.540

Kline, S., \& Rosenberg, N. (1986). An overview of innovation. In R. Landau \& N. Rosenberg (Eds.), The positive sum strategy (pp. 275-306). Washington: National Academy Press.

Lau, C.-M., \& Woodman, R. W. (1995). Understanding organizational change: a schematic perspective. The Academy of Management Journal, 38(2), 537-554. http://dx.doi.org/10.2307/256692

Lusch, R. F., Vargo, S. L., \& Tanniru, M. (2010). Service, value networks and learning. Journal of the Academy of Marketing Science, 38(1), 19-31. http://dx.doi.org/10.1007/s11747-008-0131-z

Mansury, M. A., \& Love, J. H. (2008). Innovation, productivity and growth in US business services: a $\begin{array}{llll}\text { firm-level } \quad \text { analysis. } & \text { Technovation, }\end{array}$ http://dx.doi.org/10.1016/j.technovation.2007.06.002

Marsh, H. W., Lüdtke, O., Muthén, B., Asparouhov, T., Morin, A. J., Trautwein, U., \& Nagengast, B. (2010). A new look at the big five factor structure through exploratory structural equation modeling. Psychological Assessment, 22(3), 471-491. http://dx.doi.org/10.1037/a0019227 
Marsh, H. W., Nagengast, B., Morin, A. J., Parada, R. H., Craven, R. G., \& Hamilton, L. R. (2011). Construct validity of the multidimensional structure of bullying and victimization: an application of exploratory structural equation modeling. Journal of Educational Psychology, 103(3), 701732. http://dx.doi.org/10.1037/a0024122

Miles, I. (2005). Innovation in services. In J. Fagerberg, D. C. Mowery, \& R. Nelson (Eds.), The Oxford handbook of innovation (pp. 433-458). Oxford: Oxford University Press.

Morrar, R. (2014). Innovation in services: a literature review. Technology Innovation Management Review, 4(4), 6-14. Retrieved from http://timreview.ca/article/780

Muthén, L., \& Muthén, B. (2010). Mplus user's guide (6th. Ed.). Los Angeles, CA: Muthén \& Muthén.

Pasquali, L. (2010). Testes referentes a construto: teoria e modelos de construção. In L. Pasquali, L. e Cols., Instrumentação psicológica: fundamentos e práticas (pp. 165-198). Porto Alegre: Artmed.

Peters, M., Schneider, M., Griesshaber, T., \& Hoffmann, V. H. (2012). The impact of technology-push and demand-pull policies on technical change - does the locus of policies matter?. Research Policy, 41(8), 1296-1308. http://dx.doi.org/10.1016/j.respol.2012.02.004

Poole, M. S., \& Van de Ven, A. H. (2004). Handbook of organizational change \& innovation. USA: Oxford Press.

Robertson, P., Roberts, D., \& Porras, J. (1993). Dynamics of planned organizational change: assessing empirical support for a theoretical model. Academy of Management Journal, 36(3), 619-634. http://dx.doi.org/10.2307/256595

Rubalcaba, L. (2007). The new service economy: challenges \& policy implications for Europe. Cheltenham: Edward Elgar Publishing.

Salvato, C., \& Rerup, C. (2010). Beyond collective entities: multilevel research on organizational routines and capabilities. Journal of Management, 37(2), 468-490. http://dx.doi.org/10.1177/0149206310371691

Schmookler, J. (1966). Invention and economic growth. Cambridge: Harvard University Press.

Schumpeter, J. A. (1934). The theory of economic development: An inquiry into profits, capital, credit, interest, and the business cycle (Vol. 55). New Brunswick: Transaction Publishers.

Staats, B. R., Brunner, D. J., \& Upton, D. M. (2011). Lean principles, learning, and knowledge work. Journal of Operations Management, 29(5), 376-390. http://dx.doi.org/10.1016/j.jom.2010.11.005

Steinmueller, W. (1995). The U.S. software industry: an analysis \& interpretive history. The Netherlands: MERIT - Maastricht Economic Research Institute on Innovation \& Technology.

Timmerman, M. E., \& Lorenzo-Seva, U. (2011). Dimensionality assessment of ordered polytomous items with parallel analysis. Psychological Methods, 16(2), 209-220. https://dx.doi.org/10.1037/a0023353

Toivonen, M., \& Tuominen, T. (2009). Emergence of innovations in services. The Service Industries Journal, 29(7), 887-902. http://dx.doi.org/10.1080/02642060902749492

Vargo, S. L., \& Lusch, R. F. (2004). Evolving to a new dominant logic for marketing. Journal of Marketing, 68(1), 1-17. http://dx.doi.org/10.1509/jmkg.68.1.1.24036

Vence, X., \& Trigo, A. (2009). Diversity of innovation patterns in services. The Service Industries Journal, 29(12), 1635-1657. http://dx.doi.org/10.1080/02642060902793631 
Verleye, K. (2015). The co-creation experience from the customer perspective: its measurement and determinants. Journal of Service Management, 26(2), 321-342. http://dx.doi.org/10.1108/JOSM09-2014-0254

\section{Authors' Profiles}

\section{Marina Figueiredo Moreira}

UnB, Prédio da FACE, sala A1 05/4, 70910-900, Brasília, DF, Brazil. E-mail address: marinamoreira.adm@gmail.com

Tomás de Aquino Guimarães

UnB, Campus Darcy Ribeiro, edifício FACE, Asa Norte, 70910-900, Brasília, DF, Brazil. E-mail address: tomas.aquino.guimaraes@gmail.com

Jean Philippe

Aix Marseille Université, Aix-en-Provence, 13621, France. E-mail address: jean.philippe@univ-amu.fr 